\title{
Improved thermal design methodology for wind power converters
}

\author{
Fei YANG (ه), Liang GUO
}

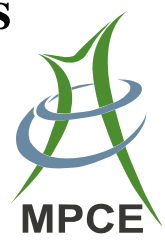

\begin{abstract}
This paper presents an improved thermal design methodology for wind power converters. It combines analysis and experimental thermal design tools, including heat transfer correlations, flow network modeling (FNM), computational fluid dynamics (CFD), and experimental measurement techniques. Moreover, a systemic product development process is introduced and an effective combination between the product development process and the thermal design methodology is achieved. The draft CFD modeling at the initial design stage is done. Furthermore, it uses the detailed CFD modeling and experimental measurement techniques to provide a higher degree of accuracy at latter design stages. The key advantage of the improved methodology is its emphasis on the use of varied design tools, each of which is actively applied at its optimal point in the proposed product development process. Thus, during the earlier stages of the product development process, the thermal risk is systematically reduced, and longterm reliability of products is maintained in a higher degree.
\end{abstract}

Keywords Flow network modeling (FNM), Computational fluid dynamics (CFD), Prototype, Simulation, Experimental measurement

\section{Introduction}

The ultimate goal of the thermal design is not the prediction of component temperatures, but rather the reduction of risk, which is thermally associated to the product [1]. This risk, inherent to today megawatt level wind power

Received: 20 May 2013 / Accepted: 1 August 2013 / Published online: 25 October 2013

(C) The Author(s) 2013. This article is published with open access at Springerlink.com

F. YANG, L. GUO, NARI Technology Development Co., Ltd., Nanjing 210061, China

$(\bowtie)$ e-mail: yangfei1@sgepri.sgcc.com.cn converters, especially the power cabinet involving insulated gate bipolar transistor (IGBT) modules, is manifested in compromised designs that cannot satisfy projected schedules due to unforeseen thermal and/or reliability issues. Therefore, thermal engineers should use temperature and airflow predictions to uncover the potential risk areas and develop feasible solutions as early as possible in the product design process. Many methods are helpful during this process, including heat transfer correlations, flow network modeling (FNM), computational fluid dynamics (CFD), and experimental measurement techniques.

This paper begins with an overview of the thermal design methodology and product development process. Direct application of an improved methodology to the thermal design for a megawatt level wind power converter is discussed. Numerical modeling and empirical results are presented and compared, followed by a discussion of method improvement in the future product design.

Biber and Belady [2] first introduced a thermal design methodology which had later evolved into the "enhanced product design cycle" method [3]. According to this methodology, the development cycle comprises three distinct phases: concept development, detailed design and hardware test. During each phase, the most practical and efficient thermal design tools are employed.

\subsection{Concept development}

The concept development phase is the initial stage in the product design cycle. This phase is characterized by rapidly changing product layouts and requirements, as representatives from all disciplines meeting to discuss requirements and to brainstorm. At this stage, the responsibilities of thermal designers include:

1) Completing an original mechanical layout capable of supporting the power dissipation of units; 
2) Completing the design and selection of thermal related parts (fans, heat sinks, main power components);

3) Identifying the areas with thermal risks and proposing necessary design requirements to reduce these risks.

Based upon their ease of use, quick solution times and input data which are limitedly required (usually geometry and fluid data only), the common tools used in this phase are generalized correlations for heat transfer and fluid flow, and FNM techniques [3-5].

Though FNM techniques are easy ones, thermal engineers are still required for comprehensive fluid mechanics foundation and adequate thermal design experience in order to build two-dimensional (2D) flow paths in the system. Some specialized data, such as heat transfer coefficients, interface thermal resistances and system flow resistances, are selected and calculated by thermal engineers. For engineers with limited professional background, it is difficult to build this kind of model. Moreover, FNM cannot solve technical problems of three-dimensional (3D) flow paths, or additional modeling may be required if such modeling exists.

\subsection{Detailed design}

Once the initial layout is confirmed, the detailed design work begins. Here, thermal analysis is oriented in further details, while results are more refined. This is the preparation for actual prototype sample building. The thermal designers work with other engineers together to determine the product design details and identify the areas with thermal risks within the product. Experimental measurements of thermal related parts may be required as inputs for models, or accurate information from vendors is needed. After this phase, thermal engineers must have enough confidence to proceed into the prototype sample building stage.

Tools commonly used in the electronics industry for the detailed thermal design are CFD and finite element analysis (FEA) solvers. Typically, the 3D modeling or existing simplified 3D computer aided design (CAD) models may be required. CFD solvers marked for the electronics industry, such as Fluent [6] and Flotherm [7], incorporate the ability to perform heat transfer calculations and fluid flow solutions. Users should be able to deal with various details in the CFD modeling, including system boundary condition input, power component modeling and model grid subdivision [8-11], etc. In addition, users need to analyze simulation results, dig deeply into critical areas, and offer design suggestions for actual products.

\subsection{Hardware test}

Once the prototype product is available, the hardware test phase begins. The designers' goal at this stage is to experimentally measure critical components and risk factors in the product to verify the design. Additionally, measurements are compared with estimates to calibrate or fine-tune earlier models. These comparisons are used to determine the accuracy of initial predictions and to assist designers to develop the thermal intuition.

While the most commonly used tool for temperature measurement is thermocouple, other tools, such as infrared imaging technique and optical radiation meter, are also available. Detailed information can be found in [12, 13].

The air speed measurement is also valuable during this phase. Hot-wire anemometer is the normal tool in the electric device field. It can capture precise and repeatable flow speed, but needs clean testing condition. The impeller anemometer is another easily operated tool for the main flow channel, but it is unsuited for breeze testing.

\section{Product development process}

A systemic product development process defines the key process steps in the design and development of the entire product for customers. A successful process should meet the following goals [14]:

1) Design and development schedules should be optimized for cost, quality and delivery, to meet customers' needs or to exceed customers' expectation.

2) The design should meet all of the customers' specification and internal requirements; any deviation should be confirmed and approved by customers with written feedback.

3) The product should be designed to meet the company's internal requirements for manufacturing ability, quality and reliability.

Based on the wind power converter design experience and referenced development process from some international companies, the proposed systemic product development process is shown in Fig. 1.

Referring to Fig. 1, six major development stages are defined as follows: request for quotation (RFQ), prototype, engineering verification test (EVT), design verification test (DVT), pilot, and mass production stages. Regarding the proposed product development process, the design team can follow or skip any of stages in the development cycle.

At the RFQ and prototype stages, the design team provides technical proposals, detailed quotations and prototype samples, which are the design foundation for the total product development process. Thus, this is where thermal engineers provide the most important input for product design. At latter stages, the thermal designers' 


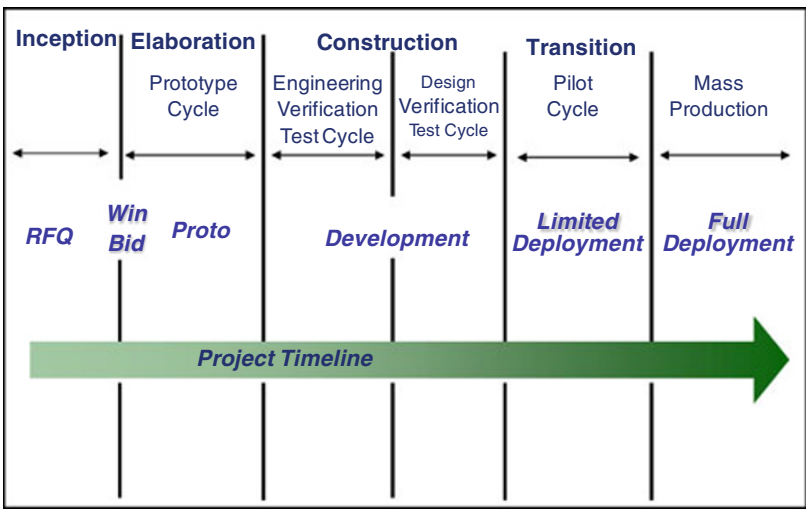

Fig. 1 Product development process

responsibility turns into experiment measurement and simulation model optimization.

\section{Power cabinet design: improved methodology}

The initial "enhanced product design cycle" method is shown in Fig. 2.

The improved methodology integrates the "enhanced product design cycle" method into the proposed product development process of the thermal design for wind power converters. It introduces the draft CFD modeling at the concept stage, and focuses on the detailed CFD modeling at the design stage. In this way, each step is validated. Thus thermal designers can test their intuition and assumptions in the earlier work.

\subsection{Concept development phase}

Corresponding to the concept development, there is an RFQ stage in product development process. At the RFQ stage, the bill of materials (BOM) and product technical proposals

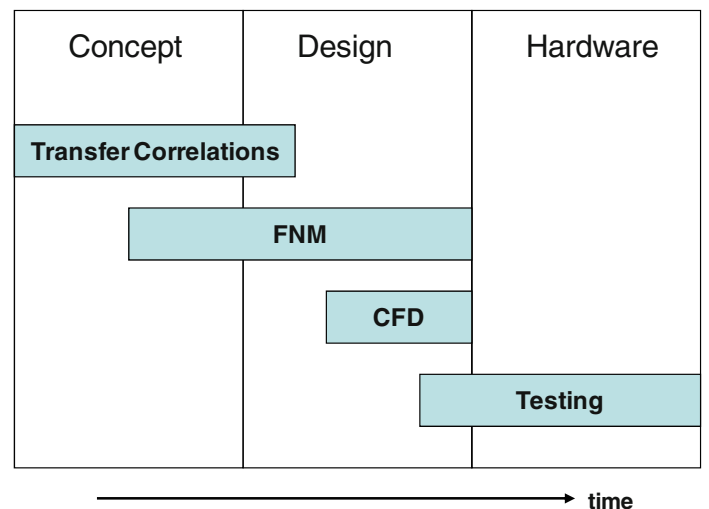

Fig. 2 Enhanced product design cycle [3] are main outputs of the design team. The design team includes electronic, mechanical and thermal engineers.

Since the wind power converter is to maintain "a long life" of 20 years, the thermal performance and the reliability of products are of the utmost importance. Especially, as a key section in the converter design, the power cabinet design is the primary element at the beginning.

The architecture design of the power cabinet begins with IGBT power module selection (to meet the customers' specification), system cabinet size and price consideration. After several days' work, one power module is selected finally.

IGBT modules are the pressure contact ones without base plates. The direct bonded copper (DBC) substrate is not soldered to the base plate. Instead, it is pressed directly to the heat sink. The elimination of a base plate assures the high temperature cycling capability (no solder fatigue caused by the thermal expansion coefficient mismatch) and a low thermal resistance [15].

Six IGBT modules are tired upon a power cabinet. The lower group with three modules (Modules A, B, C) just like a sandwich for the motor side, which is air-forcedly cooled by a radial fan. The upper group with three modules (Modules E, F, G) is for the grid side, which uses another radial fan as well. The power cabinet with two main groups is designed by using generalized empirical correlations, geometric data from mechanical layout drawings and vendors' specifications. The power cabinet layout is modeled by using a commercial FNM solver, called the MacroFlow, as shown in Fig. 3.

Airflow estimates from the flow network models are used to predict the airflow rate through each power module region, as well as to estimate the surface and junction temperatures of each power module heat sink. The

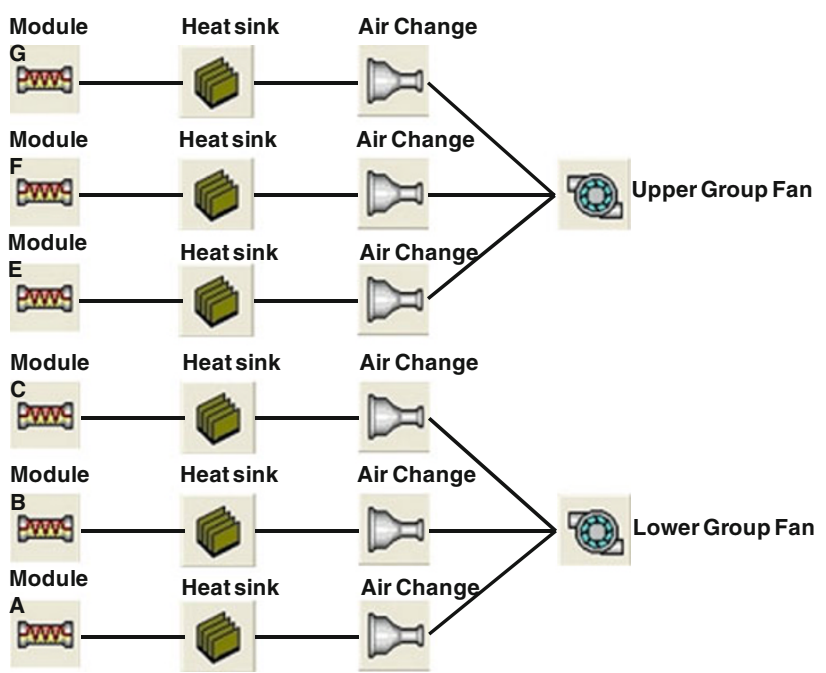

Fig. 3 FNM used in the modeling of a power cabinet 
maximum junction temperature of an IGBT module is $150{ }^{\circ} \mathrm{C}$ in the data sheet. Considering the general derating in the converter field, it is determined to be $105^{\circ} \mathrm{C}$. Worstcase IGBT module temperature is estimated with the use of extrusion heat sink and the thermal interface data is described by (1) [16-19]. The thermal resistance $\Theta$, is defined by (2).

$T_{j}=\left(T_{a}\right)_{\max }+\left(\Theta_{j c}+\Theta_{c h}+\Theta_{h a}\right) P_{\max }$

$\Theta=\Delta T / P$

where $T_{j}$ is the junction temperature $\left({ }^{\circ} \mathrm{C}\right) ; T_{a}$ is the ambient temperature $\left({ }^{\circ} \mathrm{C}\right) ; \Theta_{j c}$ is the thermal resistance between the junction and the case $\left({ }^{\circ} \mathrm{C} / \mathrm{W}\right) ; \Theta_{c h}$ is the thermal resistance between the case and the heat sink $\left({ }^{\circ} \mathrm{C} / \mathrm{W}\right) ; \Theta_{h a}$ is the thermal resistance between the heat sink and the ambient $\left({ }^{\circ} \mathrm{C} / \mathrm{W}\right) ; P_{\max }$ is the maximum power loss $(\mathrm{W}) ; \Delta T$ is the temperature difference $\left({ }^{\circ} \mathrm{C}\right)$; and $P$ is the power loss $(\mathrm{W})$.

In this manner, the minimum required airflow through each power module is determined. Then the total air volume at the working point of every radial fan is gained simultaneously. Based on the estimation above, two radial fans are chosen initially.

Then, thermal engineers could provide the main BOM on the thermal design aspect. However, at the RFQ stage, it is critical to ensure the accuracy of commercial quotation. The big error range using a FNM tool is a potential risk because of difficulties on estimation of system resistances and airflow distribution. Here, introducing the draft CFD model in advance is a good option. Then, thermal designers could verify the fan selection and airflow distribution with ease, and ensure that each power model will get enough air volume, while reducing the thermal risk because of improper fan selection at the RFQ stage.

The draft CFD modeling is accomplished by using a commercial CFD software package, called the Flotherm. The CFD modeling includes two groups: the motor-side modules and the gird-side modules.

The IGBT modules are directly derived from a specific 3D model on website. Regarding two flow channels, their sizes and specific geometry are not designed at the system level. Instead, two simple cubic channels are modeled to substitute the actual structure. Additionally, the CFD model is not generally solved for heat radiation effects because heat transfer and convection are main ways in a power cabinet. In this manner, the simplified system-level CFD model is constructed and solved. The system-level flow distribution section is shown in Fig. 4.

Referring to the simulation data of draft CFD modeling, the flow distribution in each power module is average. It is proved that two chosen radial fans could meet the thermal design requirement at the RFQ stage.

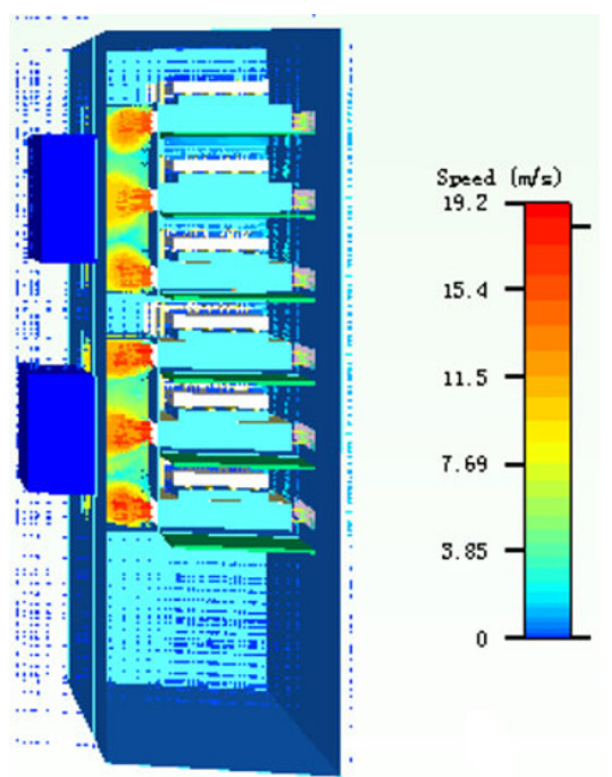

Fig. 4 Flow distribution section in the draft CFD modeling

\subsection{Detailed design phase}

Corresponding to the detailed design, there is a design period of prototype stage in the product development process. Once the commercial contract is signed and the conceptual design is approved by the customers, the thermal designers begin to concentrate on the areas with thermal risks identified in the initial modeling. The emphasis is placed on developing the draft CFD model at the RFQ stage. In order to do this, more detailed modeling techniques are employed. Furthermore, the result of detailed CFD simulation instructs the prototype product preparation.

Compared with the draft CFD modeling, the detailed CFD modeling begins to set up with an actual 3D structure in order to simulate the airflow distribution and the junction temperature of each power module. Besides, accurate power loss data, detailed flow channel structures and fan positions are determined. The system-level flow and the temperature distribution section are shown in Fig. 5.

\subsection{Hardware test phase}

Corresponding to the hardware test, there is a test period of prototype stage in the product development process. Once a prototype product is available, the thermal designers shift their focus once again. The emphasis is moved to temperature collection and airflow data measurement in the actual system. The prototype product is shown in Fig. 6.

The system is fully instrumented with thermocouples in order to obtain the thermal profile of power modules. Each 


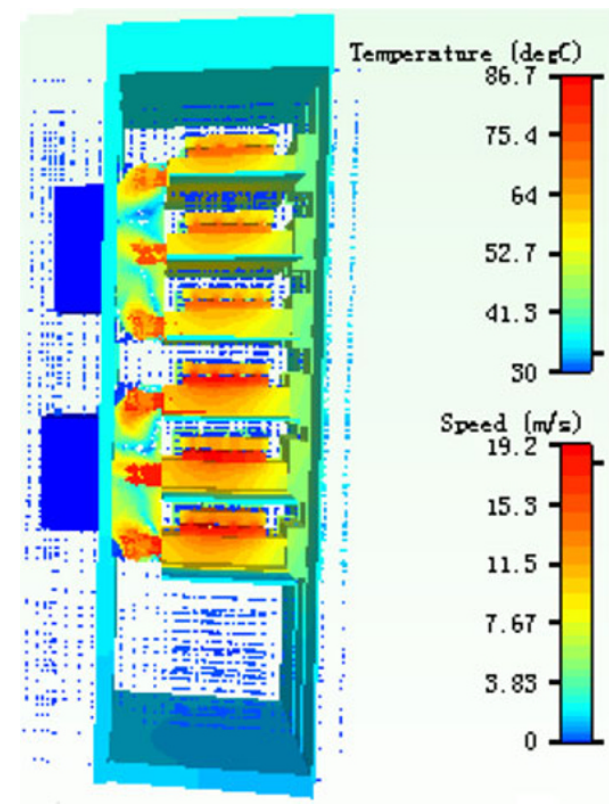

Fig. 5 Flow and temperature distribution section in the detailed CFD modeling

inlet of power module heat sinks is tested by an impeller anemometer. The testing conditions are $2,000 \mathrm{~m}$ altitude, $30{ }^{\circ} \mathrm{C}$ ambient and maximum power using (1). Extrapolated results are compared with component specifications for design verification.

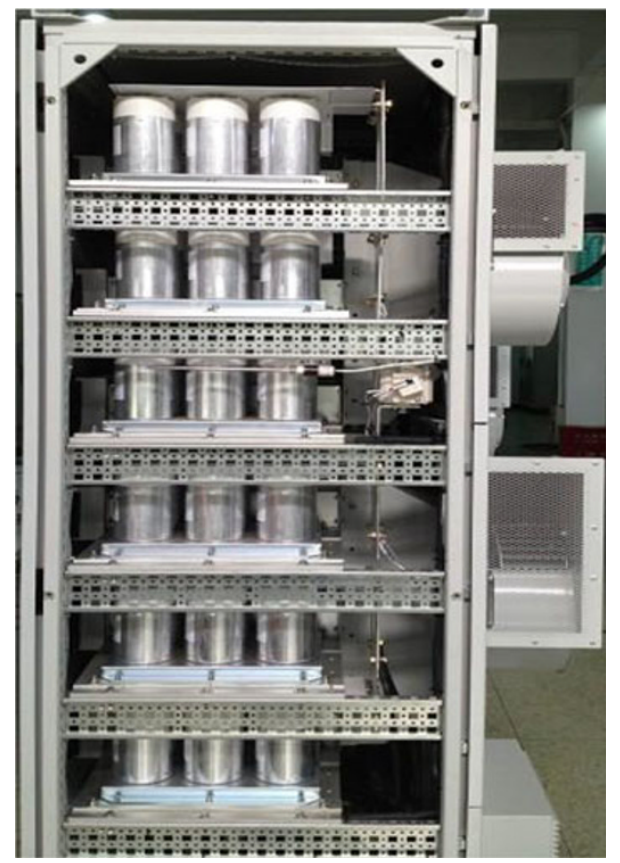

Fig. 6 Prototype sample of a power cabinet

\section{Results}

\subsection{Airflow}

Volumetric airflow predictions of FNM, draft CFD modeling, detailed CFD modeling, and measured values are compared in Table 1.

Airflow predictions are very close by using the draft and the detailed CFD modeling because of the simple structure of two main flow channels. The similar flow channels in that two phase results in the close airflow predictions. Moreover, it validates the significance to introduce the draft CFD modeling at the RFQ stage.

Airflow predictions based upon FNM and CFD modeling are lower than the measured airflow values in the prototype system. There are some reasons for these deviations. First, the 2D FNM technique cannot completely represent the 3D flow present there. Airflow estimates taken from the flow network models are functional requirement for the system fan selection. Considering the system airflow redundancy and commercial quotation, the thermal engineer usually chooses the higher level fans at the RFQ stage. That explains the reason why CFD predictions are bigger than FNM results. Secondly, it is difficult to build a precise CFD modeling because of the complex airflow distribution in the actual system. In general experience, the simulation results based on the software Flotherm are conservative. That is the possible reason why CFD predictions are less than experimental results.

The increasing tendency of airflow data from FNM predictions to measured values are seen in Table 1. It reflects the redundancy design idea at earlier stages, and relatively reduces the thermal design risk.

\subsection{Temperature}

Junction temperature estimates are compared with measured values in Table 2 .

As shown in Table 2, junction temperature predictions reflect the same rules with airflow: measured values are

Table 1 Volumetric airflow predictions

\begin{tabular}{lllll}
\hline $\begin{array}{l}\text { Power module } \\
\text { section }\end{array}$ & \multicolumn{2}{l}{ Airflow predictions $\left(\mathrm{m}^{3} / \mathrm{h}\right)$} & \multirow{2}{l}{$\begin{array}{l}\text { Measured airflow } \\
\text { values }\left(\mathrm{m}^{3} / \mathrm{h}\right)\end{array}$} \\
\cline { 2 - 4 } & FNM & $\begin{array}{l}\text { Draft } \\
\text { CFD }\end{array}$ & $\begin{array}{l}\text { Detailed } \\
\text { CFD }\end{array}$ \\
\hline Module A & 270.4 & 363.7 & 364.1 & 451.4 \\
Module B & 274.3 & 358.2 & 363.6 & 460.9 \\
Module C & 270.2 & 358.4 & 361.0 & 427.7 \\
Module E & 204.5 & 327.6 & 317.9 & 403.9 \\
Module F & 210.6 & 326.4 & 315.8 & 413.4 \\
Module G & 203.6 & 325.3 & 312.5 & 403.9 \\
\hline
\end{tabular}


Table 2 Component junction temperature at $30{ }^{\circ} \mathrm{C}$

\begin{tabular}{llll}
\hline Power module section & \multicolumn{3}{l}{ Junction temperature $\left({ }^{\circ} \mathrm{C}\right)$} \\
\cline { 2 - 4 } & FNM & Detailed CFD & Measured \\
\hline Module A & 98.4 & 85.6 & 75.42 \\
Module B & 95.2 & 86.9 & 69.94 \\
Module C & 97.2 & 86.2 & 69.55 \\
Module E & 96.4 & 74.6 & 80.53 \\
Module F & 93.5 & 74.4 & 77.59 \\
Module G & 95.4 & 72.4 & 79.52 \\
\hline
\end{tabular}

better than temperature predictions based upon FNM and CFD. The volumetric airflow is the key factor to affect the junction temperature of a IGBT module. The decreasing tendency of temperatures from FNM predictions to measured values indicates the redundancy design idea again.

Although there are discrepancies between the measured temperatures and the predicted values, the goal of the design is accomplished: all measured temperatures are lower than $105^{\circ} \mathrm{C}$. As a result, the product has been successfully released, thus it requires no changes to the system.

\section{Conclusions}

A systemic thermal design methodology is presented and applied to the design of the power cabinet in a megawatt level converter. The improved methodology combines the product development process tightly, and supports the document approval at the RFQ stage, while reducing the systematic risk through application of available thermal design tools and techniques at earlier stages. For the design of a power cabinet, the methodology has key advantages:

1) Decreasing the commercial and design risk at the RFQ stage through comprehensive application of FNM and draft CFD modeling;

2) Utilizing the commendable combination between the thermal design methodology and the product development process;

3) Applying various thermal design tools to reduce the system thermal risk and maintain the long-term reliability of products.

Finally, through enormous frequent applications in different cabinets and experience accumulation, the improved thermal methodology will play an important role in the future wind power converter design.
Open Access This article is distributed under the terms of the Creative Commons Attribution License which permits any use, distribution, and reproduction in any medium, provided the original author(s) and the source are credited.

\section{References}

[1] Belady C, Minichiello A (2003) Effective thermal design for electronic systems. Electron Cool Mag 9(2):16-21

[2] Biber C, Belady C (1997) Pressure drop prediction for heat sinks: What is the best method? In: Proceedings of the Pacific Rim/ASME international electronic packaging technical conference (INTERpack'97), Kohala Coast, HI, USA, 15-19 Jun 1997

[3] Belady C (1999) Improving productivity in electronics packaging with flow network modeling (FNM). Electron Cool Mag 5(1):36-40

[4] Ellison G (1984) Thermal computations for electronic equipment. Van Nostrand Reinhold Company, New York

[5] Minichiello A (2000) Flow network modeling: A case study in expedient system prototyping. In: Proceedings of the 7th intersociety conference on thermal and thermomechanical phenomena in electronic systems (ITHERM'00), Vol 1, Las Vegas, NV, USA, 23-26 May 2000, pp 70-77

[6] Fluent corporate website. http://www.fluent.com

[7] Flotherm corporate website. http:// www.mentor.com

[8] Patel CD, Belady CL (1997) Modeling and metrology in high performance heat sink design. In: Proceedings of the 47th electronic components and technology conference (ISPS'97), San Jose, CA, USA, 18-21 May 1997, pp 296-302

[9] He Y (2008) Application of flotherm in thermal analysis on electronic equipments. Electron Qual 1:39-40 (in Chinese)

[10] Tiersten HF, Sham TL, Lwo BJ, et al (1993) A global-local procedure for the heat conduction analysis of multichip modules. In: Proceedings of the 1993 ASME international electronics packaging conference, Vol 1, Binghamton, NY, USA, 29 Sept-2 Oct 1993, pp 103-118

[11] Oda J, Sakamoto J (1998) Applications of FEM for multiple laminated structure in electronic packaging. Finite Elem Anal Des 30(1/2):147-162

[12] Moffat RJ, Ortega A (1997) Experimental methods in air cooling of electronics. In: Proceedings of the 13th annual IEEE semiconductor thermal measurement and management symposium, Austin, TX, USA, 28-30 Jan 1997, pp 15-16

[13] Ortega A, Moffat R (2000) Experimental methods in air cooling of electronics. In: Proceedings of the 7th intersociety conference on thermal and thermomechanical phenomena in electronic systems (ITHERM'00), Vol 1, Las Vegas, NV, USA, 23-26 May 2000

[14] Emerson corporate website. http://www.emersonnetworkpower. com.cn

[15] Ye H, Lin M, Basaran C (2002) Failure modes and FEM analysis of power electronic packaging. Finite Elem Anal Des 38(7):601-612

[16] Hanreich G, Nicolics J (2001) Measuring the natural convective heat transfer coefficient at the surface of electronic components. In: Proceedings of the 18th instrumentation and measurement technology conference (IMTC'01), Vol 2, Budapest, Hungary, 21-23 May 2001, pp 1045-1050

[17] Aghazadeh M, Mallik D (1990) Thermal characteristics of single and multi-layer high performance PQFP packages. IEEE Trans Compon Hybrid Manuf Technol 13(4):151-153

[18] Hassselman DPH, Donaldson KY, Barlow FD (2000) Interfacial thermal resistance and temperature dependence of three 
adhesives for electronic packaging. IEEE Trans Compon Pack Technol 23(4):175-179

[19] Zhang X, Wong EH (2002) Thermo-mechanical finite element analysis in a multichip build up substrate based package design. Microelectron Reliab 44(4):611-619

\section{Author Biographies}

Fei YANG was born in China, in 1975. He received the B.E. degree in Mechanical Manufacture and Technology from Southwest Jiaotong University in 1998, and the M.E. degree in Engineering Mechanics from Dalian University of Technology in 2005. He worked for a number of years on telecom devices in Huawei Technologies Co., Ltd., and power supply units in Emerson Telecom Power, U.S. In 2012, he joined NARI Technology Development Co., Ltd. as an engineer. His main research interests are focused on thermal design, environmental suitability and structural design.

Liang GUO was born in China, in 1982. He received the B.E. degree and the M.E. degree in Power Electronics from Nanjing University of Aeronautics and Astronautics in 2005 and in 2008, respectively. He is currently an engineer in NARI Technology Development Co., Ltd. His research interests include power electronic converters applied to renewable energy sources, power systems and energy efficiency. 